\title{
Seroprevalence and some Demographic Factors Associated with Toxoplasma gondii Infection among Male Population in Duhok Province/Iraq
}

\author{
Janan M. Salih ${ }^{1}$ \\ Wijdan M.S. Mero ${ }^{2}$ \\ Souzan H. Eassa ${ }^{1 *}$
}

Received 2/9/2019, Accepted 5/11/2019, Published 1/6/2020

This work is licensed under a Creative Commons Attribution 4.0 International License.

\begin{abstract}
:
The present study aims to investigate the seroprevalence rate of Toxoplasma gondii infection and its relation to some demographic factors among males in Duhok province/Iraq. A total of 424 random blood samples were collected from the male population of different ages (18-60) years and different socialeconomic classes. Out of 424 samples examined, 108 (25.47\%) were seropositive to the anti- T. gondii antibodies; 88 (20.75\%) were found seropositive for IgG, while 20 (4.72\%) samples were seropositive for IgM. Regarding occupation, the highest percentage for chronic toxoplasmosis was reported in workers followed by policemen and pensioners at rates of $23.96 \%, 23.6 \%$, and $23.07 \%$, respectively. The age group 18-30 years showed the highest seropositive rate which was $26.6 \%$; the seropositivity rate decreased with the increase of age. Regarding the blood groups, the highest percentage of $\mathrm{IgG}$ was reported in both $\mathrm{O}^{+}$and $\mathrm{B}^{-}$ groups, which were $23.2 \%$ and $23.1 \%$, respectively. The higher rate of seropositivity was observed among married males $(21.32 \%)$ as compared to unmarried males (19.05\%) and fertile (22.3\%) versus sterile males $(12.5 \%)$. Concerning IgM antibodies, the highest seropositivity $(9.4 \%)$ was reported in infertile males. The results of this study showed the importance of demographic factors to the epidemiology of $T$. gondii in males, which support the role of public health in the control of infectious diseases.
\end{abstract}

Key words: Fertility, Male, Seroprevalence, Toxoplasmosis.

\section{Introduction:}

Toxoplasmosis is a significant zoonotic disease caused by an obligate intracellular protozoan parasite called Toxoplasma gondii ( $T$. gondii), which causes infections in all warm-blooded animals (1). Toxoplasmosis has a worldwide distribution, and it's been estimated that $T$. gondii infects about one-third of the human population (2). Humans and other animals, including birds can serve as intermediate hosts, while felids like domestic and wild cats are considered as definitive hosts (3). There is a worldwide variation in the prevalence of toxoplasmosis, being higher in underdeveloped countries than developed ones (4). This variation in prevalence can be explained by several factors including the climate, number and presence of cats, age, nutritional and factors, and cultural and ethnic practices $(5,6)$. Direct contact with cats is not required for transmission due to the longevity of oocysts in the environment (5).

${ }^{\mathrm{T}}$ Department of Microbiology, College of Medicine, University of Duhok, Duhok Province, Iraq.

${ }^{2}$ Department of Biology, Faculty of Science, University of Zakho, Duhok Province, Iraq.

"Corresponding author: souzan.eassa@uod.ac *ORCID ID: https://orcid.org/0000-0003-1433-2957
Scientific studies have reported that $T$. gondii infections in males affected reproductive parameters; the latest studies have concluded that transmission of toxoplasmosis can occur by sexual contact between couples (7). Furthermore, other studies have demonstrated that sexual transmission of $T$. gondii can cause complications such as infertility (8). The fertility of males can be affected by congenital or acquired urogenital abnormalities, urogenital tract infections, increased scrotal temperature, endocrine disturbances, genetic abnormalities, and immunological factors (9).

In the Duhok province, limited studies have been performed on the seroprevalence of toxoplasmosis. These studies concentrated on the prevalence of toxoplasmosis among females without considering its effects among males (10). Furthermore, they did not estimate the general epidemiological status and risk factors associated with the prevalence of this disease among males. However, recently Hussien et al. (11) studied the relationship between toxoplasmosis and male sex hormones. This study is an attempt to correlate the epidemiology of toxoplasmosis and various 
demographic factors among males using ELISA technique.

\section{Materials and Methods}

During the period from October 2016 to November 2017, a total of 424 blood samples were collected from males aged (18-60) years, which belong to different socioeconomic classes. From each person, $5 \mathrm{ml}$ of blood was withdrawn and transferred to a clean fully labeled tube, then centrifuged at $3000 \mathrm{rpm}$ for 10 minutes to separate the serum. The separated serum was dispensed into two Eppendorf tubes (fully labeled with the required information according to the questionnaire sheet designed for the study) and stored at $-20^{\circ} \mathrm{C}$.

The seroprevalence of Toxoplasma antibodies was determined using the ELISA technique.

The ELISA kits were supplied by Bioactive Company (Germany). The procedure was done according to the instructions provided with kit. The work was performed at the Central Blood Bank Laboratory in Duhok province.

\section{Statistical Analysis}

The data was analyzed based on age group, occupation, marital status, blood groups, and fertility, using online Open Epi program: Open Source Epidemiologic Statistics for Public Health (12) Version 3.01 www.OpenEpi.com.

\section{Results:}

The overall seroprevalence rate of $T$. gondii among the 424 blood samples was 108(25.47\%), of which $88(20.75 \%)$ were seropositive for $\mathrm{IgG}$, and $20(4.27 \%)$ were seropositive for $\operatorname{IgM}$; the remaining samples were negative as shown in Table 1.

Table 1. The seropositivity rate of anti-Toxoplasma IgG, IgM antibodies in males using ELISA technique.

\begin{tabular}{ccccccc}
\hline \multirow{2}{*}{ No. of tested Samples } & \multicolumn{2}{c}{ Total positive } & \multicolumn{2}{c}{ IgG + } & \multicolumn{2}{c}{ IgM + } \\
\cline { 2 - 7 } & No. & $\%$ & No. & $\%$ & No. & $\%$ \\
424 & 108 & 25.47 & 88 & 20.75 & 20 & 4.72 \\
\hline
\end{tabular}

In terms of occupation, the highest percentage for IgG was reported in the worker's group followed by policemen and pensioners, which were $23.96 \%, 23.6 \%$, and $23.07 \%$, respectively.
While the highest percentage $(9.09 \%)$ for IgM was reported in mechanical workers group, these differences were statistically non-significant ( $p>0.05$ ) as indicated in Table 2.

Table 2. The percentage of seropositivity of anti- T. gondii IgG and IgM according to the occupation.

\begin{tabular}{cccccccc}
\hline & Samples number & \multicolumn{2}{c}{ Total positive } & \multicolumn{3}{c}{ IgG } & \multicolumn{2}{c}{ IgM } \\
\cline { 3 - 7 } Employ & & No. & $\%$ & No. & $\%$ & No. & $\%$ \\
Students & 87 & 20 & 22.99 & 17 & 19.54 & 3 & 3.45 \\
Policemen & 46 & 6 & 13.04 & 5 & 10.87 & 1 & 2.17 \\
Pensioners & 89 & 24 & 26.97 & 21 & 23.6 & 3 & 3.37 \\
Mechanic & 39 & 11 & 28.21 & 9 & 23.07 & 2 & 5.13 \\
Drivers & 11 & 3 & 27.27 & 2 & 18.18 & 1 & 9.09 \\
Workers & 19 & 4 & 21.05 & 3 & 15.79 & 1 & 5.26 \\
Farmers & 96 & 31 & 32.29 & 23 & 23.96 & 8 & 8.33 \\
Butchers & 5 & 1 & 20.00 & 1 & 20.00 & 0 & 0.00 \\
Total & 32 & 8 & 25 & 7 & 21.88 & 1 & 3.13 \\
& 424 & 108 & 25.47 & 88 & 20.75 & 20 & 4.72 \\
\hline
\end{tabular}

In terms of age, the highest seropositive percentage was observed among ages from (18-30) years, which was $26.6 \%$, and then the seropositive rate decreased with the increase of age, as shown in
Table 3. These differences were statistically nonsignificant $(\mathrm{p}>0.05)$. While IgM antibodies showed the highest rate $(8.6 \%)$ among the age group (4150) years. 
Table 3. The seropositivity rates of anti- T. gondii IgG and IgM Antibodies among different age groups.

\begin{tabular}{cccccccc}
\multirow{2}{*}{ Age Groups } & \multirow{2}{*}{ Samples number } & \multicolumn{2}{c}{ Positive samples } & \multicolumn{2}{c}{ IgG } & \multicolumn{2}{c}{ IgM } \\
\cline { 2 - 7 } $18-30$ & 120 & No. & $\%$ & No. & $\%$ & No. & $\%$ \\
$31-40$ & 174 & 35 & 29.17 & 32 & 26.7 & 3 & 2.5 \\
$41-50$ & 93 & 24 & 24.71 & 35 & 20.1 & 8 & 4.6 \\
$51-60$ & 37 & 6 & 16.22 & 5 & 13.5 & 1 & 2.7 \\
Total & 424 & 108 & 25.47 & 88 & 20.8 & 20 & 4.72 \\
& \multicolumn{2}{c}{ Chi-square 5.52} & p-value $=0.13$ & & & \\
\end{tabular}

With respect to blood groups, the highest percentage of IgG was reported among men with both $\mathrm{O}+$ and $\mathrm{B}$ - groups, which were $23.2 \%$ and $23.1 \%$ respectively, followed by $\mathrm{AB}$ - which was
20\%. This diminutive difference in results was statistically significant $(\mathrm{p}<0.05)$ as shown in Table 4.

Table 4. The seropositivity rate of anti- T. gondii IgG and IgM antibodies among different blood groups.

\begin{tabular}{lccccccc}
\hline \multirow{2}{*}{ Blood group } & Samples no. & \multicolumn{2}{c}{ Positive samples } & \multicolumn{3}{c}{ IgG } & \multicolumn{3}{c}{ IgM } \\
\cline { 2 - 7 } A+ & & No. & $\%$ & No. & $\%$ & No. & $\%$ \\
A- & 104 & 28 & 26.92 & 20 & 19.2 & 8 & 7.69 \\
B+ & 11 & 2 & 18.18 & 2 & 18.2 & 0 & 0 \\
B- & 100 & 28 & 28 & 21 & 21 & 7 & 7 \\
O+ & 13 & 4 & 30.77 & 3 & 23.1 & 1 & 7.69 \\
O- & 138 & 36 & 26.09 & 32 & 23.2 & 4 & 2.89 \\
AB+ & 14 & 2 & 14.29 & 2 & 14.3 & 0 & 0 \\
AB- & 39 & 7 & 17.95 & 7 & 17.9 & 0 & 0 \\
Total & 5 & 1 & 20 & 1 & 20 & 0 & 0 \\
& 424 & 108 & 25.47 & 88 & 20.8 & 20 & 4.72 \\
\hline
\end{tabular}

Married men showed a slightly higher overall seropositivity rate as compared to unmarried ( $25.71 \%$ versus $24.76 \%)$, but this difference was statistically non-significant $(\mathrm{p}>0.05)$. The seropositivity rate of $\mathrm{IgG}$ in married men was also slightly higher than that of unmarried men, but this difference was also statistically non-significant ( $p>0.05$ ). On the other hand, unmarried men showed a higher IgM seropositivity rate as compared to married men, but the difference between both values was, again, statistically nonsignificant $(\mathrm{P}>0.05)$ (Table 5).

Table 5. The percentage of seropositivity of anti-T. gondii IgG and IgM between married and unmarried men.

\begin{tabular}{cccccccc}
\multirow{2}{*}{ Marital status } & \multirow{2}{*}{ Samples number } & \multicolumn{2}{c}{ Positive samples } & \multicolumn{2}{c}{ IgG } & \multicolumn{2}{c}{ IgM } \\
\cline { 2 - 7 } Single & 105 & No. & $\%$ & No. & $\%$ & No. & $\%$ \\
Married & 319 & 82 & 24.76 & 20 & 19.05 & 6 & 5.71 \\
Total & 424 & 108 & 25.71 & 68 & 21.32 & 14 & 4.39 \\
& Chi-square 0.28 & \multicolumn{3}{c}{ p-value $=0.59$} \\
\end{tabular}

Fertile men showed the highest percentage of seropositivity for Toxoplasma IgG antibodies $(22.3 \%)$, which was statistically significant $(\mathrm{p}<0.01 \%)$. While the highest seropositivity of $\operatorname{IgM}$ antibodies reported among infertile men was $9.4 \%$, and this difference was statistically significant $(\mathrm{p}<0.05)$ as indicated in Table 6.

Table 6. The percentage of seropositivity of $T$. gondii regarding fertility.

\begin{tabular}{|c|c|c|c|c|c|c|c|}
\hline \multirow{2}{*}{ Fertility } & \multirow{2}{*}{ Samples number } & \multicolumn{2}{|c|}{ Positive samples } & \multicolumn{2}{|c|}{$\operatorname{IgG}$} & \multicolumn{2}{|c|}{ IgM } \\
\hline & & No. & $\%$ & No. & $\%$ & No. & $\%$ \\
\hline Fertile & 287 & 75 & 26.13 & 64 & 22.3 & 11 & 3.8 \\
\hline Infertile & 32 & 7 & 21.88 & 4 & 12.5 & 3 & 9.4 \\
\hline \multirow[t]{2}{*}{ Total } & 319 & 82 & 25.71 & 68 & 21.32 & 14 & 4.39 \\
\hline & \multicolumn{3}{|c|}{ Chi-square 4.80} & $=0$. & & & \\
\hline
\end{tabular}




\section{Discussion:}

The pattern of seropositive rates in males for acute and chronic toxoplasmosis in the present study agreed, to some extent, with the study of Hussein et al. (11) conducted in Duhok province. Which also reported slightly lower rates for total and chronic seroprevalence $(22.98 \%$ and $16.35 \%)$ and a slightly higher rate $(6.25 \%)$ for acute seroprevalence of toxoplasmosis. Similarly, a study in Kirkuk by Obaid et al. (13) also reported higher rates of total and chronic seroprevalence of toxoplasmosis about (18.6\% and 11.6\%), and a lower rate $(4.6 \%)$ for acute toxoplasmosis. A study by Bahhaj R et al. (14) also reported a high seropositive rate for $\operatorname{IgG}(39.36 \%)$ and a low seropositive rate for $\operatorname{IgM}(1.06 \%)$ among healthy blood donors.

The seroprevalence rate of toxoplasmosis can be affected by many factors such as the nature of the work, the type and source of food and drinks, and the sanitary conditions of food handlers (10). These results disagreed with a study performed by Al-Bajalan et al. (15) in which the highest seroprevalence percentage was reported in the mechanic group followed by the farmer group which were $71.42 \%$ and $63.63 \%$, respectively. Also, using ELISA technique, Sarmad (16) reported a high rate $(22.73 \%)$ of toxoplasmosis among farmers living in Erbil province and attributed it to their direct contact with soil contaminated with sporulated oocysts.

Regarding age, the highest seropositive percentage was observed among ages ranging from 18-30 years, which was $26.6 \%$, and then the seropositive rate decreased significantly with the increasing age. Similarly in two studies performed in Baghdad, the first by Mahmoodet al. (6) they reported high positive rates $(24.79 \%)$ of $\mathrm{IgG}$, using ELISA, at ages ranging from 18-25 and 26-33 years, which decreased with the increase in the age. Muhsin et al. (17) also reported the highest rate of toxoplasmosis in males was at ages between 19-28 years and the lowest rate at the ages of 49- 58 years, which were $35.29 \%$ and $12.94 \%$, respectively. In the present study, IgM antibodies showed the highest rate (8.6\%) among the age group (41-50) years, while the Muhsin et al. (17) study reported the highest rate was among young ages (18-28) years and attributed it to higher activities and more significant exposure to risk factors as compared to older ages.

With respect to blood groups, the highest percentage of $\mathrm{IgG}$ was reported among men with both $\mathrm{O}^{+}$and $\mathrm{B}^{-}$groups, which were $23.2 \%$ and $23.1 \%$, respectively, followed by $\mathrm{AB}^{-}(20 \%)$. These results agree with the study of Obaid et al.(13) who reported the highest percentage of $\operatorname{IgG}$ antibodies among blood donors in group $\mathrm{A}^{+}$was $33.3 \%$ followed by $\mathrm{O}^{+}$and $\mathrm{AB}^{-}$groups $19.2 \%$ and $16.6 \%$ respectively, whereas disagreed with $\mathrm{B}^{-}$group which was $0 \%$. Moreover, in other studies in Baghdad, the highest seropositivity rates of toxoplasmosis were reported among men belonging to other blood groups such as Mahmood et al. (6) who showed that the highest prevalence was among men having $\mathrm{AB}+(41.32 \%)$ and the lowest prevalence $(15.70 \%)$ of group O+. While Abdulla et al. (18) reported the highest rate $(26.1 \%)$ among blood group $\mathrm{O}^{+}$, they attributed this difference in the results to several factors such as the possibility of the molecular mutation of strains among patients.

Married men showed a slightly higher overall seropositivity rate as compared to unmarried men ( $25.71 \%$ versus $24.76 \%$ ). The seropositivity rate of IgG in married men was also slightly higher than that of unmarried men, but the differences in seropositivity among both groups were statistically non-significant ( $>0.05$.) Moreover, unmarried men showed a higher but non-significant ( $p>0.05) \operatorname{IgM}$ seropositivity rate as compared to married men.

The present results conflict with those of AlAboody (19) in Thi-Qar who stated that chronic and acute toxoplasmosis infection in married males was significantly higher than unmarried ones, which was 55 (78.5\%), 4(5.7\%) and 10 (14.2\%), 1(1.4\%) respectively. Similarly, Muhsin et al. (17) in Baghdad, reported a significantly higher rate of chronic toxoplasmosis infection among married men as compared to unmarried men, which were,70 $(82.35 \%)$ and $15(17,64 \%)$ respectively. In Duhok province, there are no previous studies on males infected with toxoplasmosis to compare the obtained results.

Fertile men showed the highest percentage of seropositivity for Toxoplasma IgG antibodies $(22.3 \%)$, which was statistically significant $(\mathrm{p}<0.01 \%)$ while the highest seropositivity of IgM was reported among infertile men $(9.4 \%)$, which was significantly $(\mathrm{p}<0.1)$ different from unmarried. There is little information about the involvement of T. gondii with male infertility. Zhou et al. (20) reported a higher rate of toxoplasmosis in infertile human couples than infertile ones, and related it to the anti-sperm antibodies which were higher in infected couples. Also, Qi et al. (21) studied 100 cases of male sterility and found that $36 \%$ were seropositive for Toxoplasma IgG and IgM.

Dongmei et al. (22) stated that apoptosis of spermatogenic cells happens in fertile and infertile males, and they found a very close relationship between sperm apoptosis and male infertility, 
suggesting that Toxoplasma infection may cause the apoptosis of spermatogenic cells.

The present results disagree with Mahmood et al. (6) in Baghdad, who reported a higher seropositivity rate $(69.30 \%)$ of $\mathrm{IgG}$ in infertile men as compared with fertile men (30.69\%). Males infected with acute toxoplasmosis had the highest percentage of anti-Toxoplasma IgM antibodies $(85.71 \%)$ as compared to infertile (14.2\%). In contrast, different results achieved by Al-Aboody (19), in Thi-Qar, showed that fertile males had a low percentage of anti-Toxoplasma IgG antibodies while infertile males showed a high percentage about $18(30.5 \%)$ and $37(62.7 \%)$ respectively.

Different results can be obtained within the same country; this may be due to the contribution of different factors such as the source of serological test kits (which vary with manufactured companies), the study and laboratory conditions. Furthermore, nutritional behaviors vary within the same country, as well as hygienic habits, climate conditions, having pets, working or cleaning gardens, etc (23).

\section{Conclusion:}

The present study can be considered as an initial step in Duhok province to investigate the prevalence of toxoplasmosis among males from different ages, socioeconomic classes, and relation to demographic factors. Based on the outcomes of this study, we can conclude that males, much like females, can get toxoplasmosis infections. Moreover, toxoplasmosis still shows a significant threat to both genders. The current results indicate that toxoplasmosis has a high prevalence among males, especially workers who may practice poor hygienic habits and have low levels of health education, in addition to the abundance of stray cats in the community, which can contaminate the environment with the oocysts. Therefore, efforts must be made to achieve a reasonable control on food safety, especially among food handlers, and on stray cats, in order to reduce the risks of infection with toxoplasmosis.

\section{Authors' declaration:}

- Conflicts of Interest: None.

- We hereby confirm that all the Figures and Tables in the manuscript are mine ours. Besides, the Figures and images, which are not mine ours, have been given the permission for republication attached with the manuscript.

- The author has signed an animal welfare statement.
- Ethical Clearance: The project was approved by the local ethical committee in University of Duhok.

\section{References:}

1. Villard O, Cimon B, L'Ollivier C, Fricker-Hidalgo H, Godineau N, Houze S et al. Serological diagnosis of Toxoplasma gondii infection: Recommendations from the French National Reference Center for Toxoplasmosis. Diagnostic Microbiology and Infectious Disease. 2016 Jan.; 4: 22-33.

2. Mohaghegh MA, Hajar Y, Mahboobe H, Fatemeh N, Mehdi A, Hamed K, et al. Peroprevalence of Toxoplasma gondii infection among patients admitted to Al-Zahra hospital, Isfahan, Iran. J Ayub Med Coll Abbottabad. 2015 Oct.; 27(4):767-70.

3. Singh S, Congenital toxoplasmosis: Clinical features, outcomes, treatment, and prevention, J. Trop Parasitol. 2016 Jul.; 6(2): 113-122.

4. Halonen SK, Weiss LM. Toxoplasmosis. Handbook of Clinical Neurology.2013; Pp. 114: 125-145.

5. Dabritz HA, Conrad PA. Cats and Toxoplasma: Implications for Public Health Zoonoses. Public Health. 2010 Feb.; 57:34-52.

6. Mahmood SH, AL-Qadhi BN, Zghair KHZ. Prevalence of Toxoplasmosis of Males Blood Donors in Baghdad. Iraqi Journal of Science.2013; 54(4): 832-841.

7. Flegr J, Klapilová K, Kan¡ková Š. Toxoplasmosis can be a sexually transmitted infection with serious clinical consequences. Not all routes of infection are created equal. Medical Hypotheses J. 2014 Sep.; 83(3): 286-289.

8. Ab-dulla HE, Abood AS. Kadhim HS. Al-bashier NM. Al-kawaz U. The impact of toxoplasmosis on Seminal fluid analysis in association with infertility. Inter J of Scientific \& Engin Research. 2016 May; (5):70-73.

9. Dohle GR, Diemer T, Giwercman A, Jungwirth A, Kopa Z, Krausz C. Guidelines on infertility. 2010. European Association of Urology, Arnhem, Netherlands, Pp 64.

10. Murad MA, Eassa SH, Al-Saeed ATM. Detection of Toxoplasmosis Among Women With Abortion Using Molecular and Serological Tests in Duhok City. Duhok Medical Journal. 2016 Dec.; 10(2), 56-68.

11. Hussien MR, Al-Saeed ATM, Eassa SH. Toxoplasmosis seropositivity and male sex hormones. J. Immunol Infect Dis. 2018 Sep.; 5(1): 1-8.

12. Dean G, Sullivan KM. Open source epidemiologic statistics for public health. OpenEpi, version 3.01., http://www.OpenEpi.com (April 4, 2013).

13. Obaid HM, Noor aldeen MY, Mohammad LM, Jasim SS. Seroprevalence of Anti Toxoplasma gondii IgG and IgM in Healthy Blood Donors in Kirkuk City. JUBPAS. 2017; 3(25): 946-954.

14. Bahhaj R, Ahmadpour E, Mahami-Oskouei M, Fallah E, Shamsasenjan K, Safaiyan A. Toxoplasma gondii Infection and Related Risk Factors among Blood Donors in Northwest Iran. Arch Clin Infect Dis. In 
Press (In Press):e6 2005. Published online 2017 April 30. doi: 10.5812/archcid.62005

15. Al-Bajalan RR, Al-Nasiri FS, Mahmood SM. Detection of Toxoplasma gondii by latex and ELISA test in infertile and fertile men in Kalar City, Kurdistan region, Iraq. Int J Curr Microbiol App Sci. 2015; 4(10):570-85.

16. Sarmad NM. Seroprevalence of Toxoplasma gondii antibodies among farmers in Erbil Government by using enzyme-linked immunosorbent assay (ELISA). Journal of Raparin University. 2017 Mar.; 8: 4-10.

17. Muhsin SS, Mamdooh AM, Baseer AN. Seroprevalance study of Toxoplasmosis among males in Al-Ruasfa Institute of management in Baghdad Province-Iraq. IOSR J Pharm Biol Sci. 2018 Apr.; 13(2): 22-26.

18. Abdulla HE, Al-bashier NM, Al-kawaz U, AlShuwaikh AMA, Abood AS. Cross-sectional study of infertile males with toxoplasmosisin Baghdad province. Inter J Sci Engineer Res. 2015 Jan.; 6(1): 254259.
19. Al-Aboody BA. Prevalence study of toxoplasmosis among males blood donors in Thi-qar province-Iraq. Int J Re. Appl Nat Soci Sci. 2015 Nov.; 3:73-82.

20. Zhou YH, Song ML, Jiang QZ, Zhao QS, Gao WU, Shen QF, et al. Serological survey of Toxoplasma gondii infection in invalid children. Chinese J Zoonoses. 2002; 18:129-130.

21. Qi R, Su XP, Gao XL, Liang XL. Study on Toxoplasma infection in male with sterility in Shenyang China. Zhonghua Nan Ke Xue. 2005 Jul.; 11(7):503-504.

22. Dongmei X, Zhou Y, Diao W. Preliminary investigation on relationship between spermatogenic cells apoptosis and infection of Toxoplasma gondii in male in fertility. Chinese J Schistomiasis. 2005 Jun.; 6:1-20.

23. Khalil HI, Merdaw MA, Abdullah AM, El-Hashimi ZK, Al-Bashier NM, Mohemmad HJ. Estimation of Toxoplasma gondii Infection by Serological and Immunohisto-chemical Methods in Baghdad CityIraq. International Journal of Advanced Research. 2016 March; 4(4):272-278.

\section{الانتشار المصلي وبعض العوامل الديموغرافية المرتبطة بعدوى المقوسات الكوندية بين السكان الذكور في

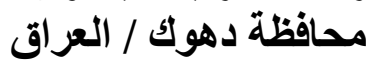
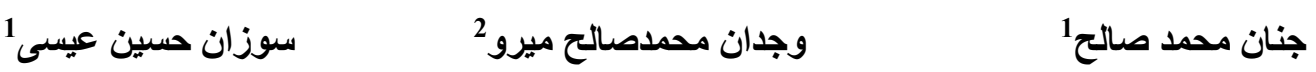

$$
\begin{aligned}
& 1 \text { قسم علم الأحياء الدقيقة، كلية الطب ، جامعة دهوك ، دهو ، دهوك، العراق. }
\end{aligned}
$$

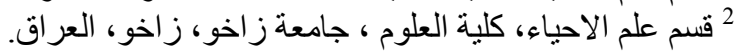

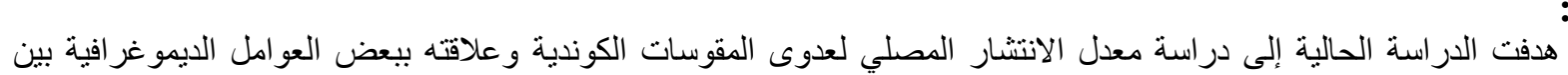
الذكور في محافظة دهوك/ العر اق. تم جمع ما مجمو عده 424 عينة دم عشو ائية من السكان الذكور من مختلف الأعمار (18-60) سنة ولنة وفئات

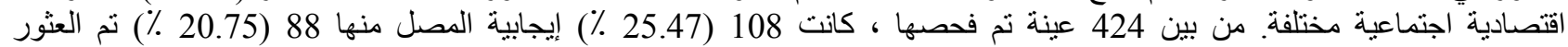

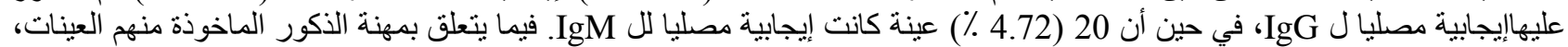

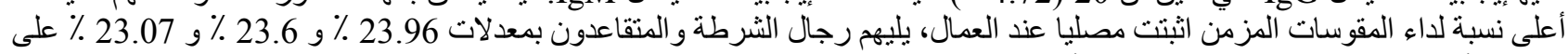

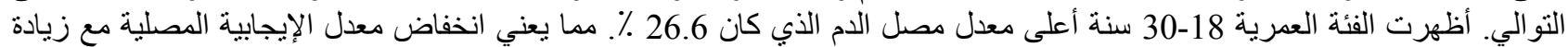

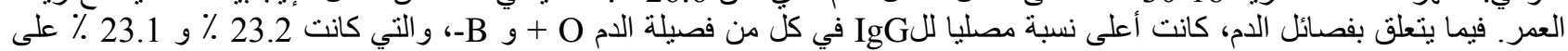

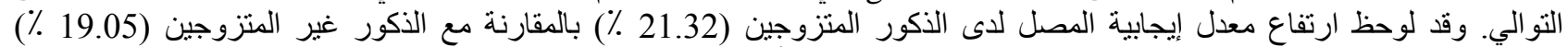

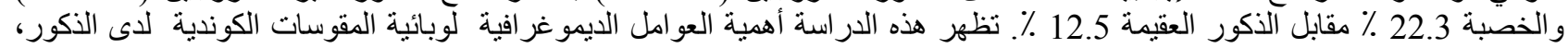
والتي تدعم دور الصحة العامة في السيطرة على الأمر اض الفعة المعدية.

$$
\text { الكلمات المفتاحية: الخصوبة، الذكور، المصلي، داء المقوسات. }
$$

